\title{
Understanding Patient Perspectives Regarding Long Acting Reversible Contraception: A Qualitative Study to Inform A Key Domain of Implementation Science
}

William C Livingood ( $\square$ William.livingood@jax.ufl.edu )

University of Florida College of Medicne Jacksonville

\section{Katryne Lukens Bull}

University of North Florida

\section{Staci Biegner}

University of Florida College of Medicne Jacksonville

Andrew M Kaunitz

University of Florida College of Medicne Jacksonville

LaRonda Howard

Northeast Florida Healthy Start Coalition

Vanessa Jefferson

Northeast Florida Healthy Start Coalition

Pia Julia Geisselmaier

University of Florida College of Medicne Jacksonville

Isabelle Michel

University of Florida College of Medicne Jacksonville

Lori Bilello

University of Florida College of Medicne Jacksonville

\section{Research Article}

Keywords: Cultural Tailoring, Focus Group, Long Acting Reversible Contraception, Motivational Interviewing, Patient Centered, Qualitative Research

Posted Date: April 28th, 2021

DOI: https://doi.org/10.21203/rs.3.rs-424042/v1

License: (c) (i) This work is licensed under a Creative Commons Attribution 4.0 International License.

Read Full License 


\section{Abstract}

Background: Evidence has continued to emerge that Long-acting reversible contraception (LARC) is highly effective in preventing unintended pregnancies and induced abortions, but utilization of LARC remains low among US women, particularly among minority and low income women.

Aims: We designed this study to develop insights into factors that can better inform urban, predominantly African American women's decisions to use LARC.

Methods: We conducted focus group interviews with women, in conjunction with a community-based organization providing programs for underserved women, in an urban southeastern U.S city with sites in predominantly African American neighborhoods.

Results: Key insights from the focus group results for healthcare providers include: the importance of framing discussions with patients within the context of the patients' goals; the need to acknowledge and respect the support systems that women rely on for child birthing and childcare; recognition of the clinician's role as a trusted and respected source of information; and the need to understand and be prepared to address much of the inaccurate and misleading information that can interfere with the patients' optimal choices for contraception.

Discussion: A critical component for applying Implementation Science theory to increase utilization of evidence based practices such as $L A R C$ requires understanding women's perspectives of the factors influencing their decisions to use LARC.

Conclusion: This study provides important insights into: 1) the potential barriers inherent in minority women's concerns about LARC, and 2) how these insights can inform implementation strategies such as patient centered counseling and education to overcome those barriers.

\section{Introduction}

Slow adoption of evidence-based science by the practice community can challenge implementation of effective public health and health care interventions, as is the case with Long Acting Reversible Contraception (LARC). Although LARC, including contraceptive implant and intrauterine devices (IUDs), is highly effective in preventing unintended pregnancies (1) and induced abortions (2), the prevalence of LARC use remains low among US women overall, particularly among minority and low income women (3-4). Despite the high contraceptive efficacy of IUDs and the implant, recent research has shown parity in overall contraception use among the races and different income groups, but with extremely low implant use (3\%) by the non-Hispanic Black population and increases in use of withdrawal as a means of contraception between 2008 and 2014 (5). This low utilization of highly effective contraceptives contributes to the sobering statistic that almost one half (45\%) of all pregnancies in US women are unintended, with the proportion higher among low income and minority women (6). 
LARC is a particularly appropriate challenge for Implementation Research, the science of closing the gap between research and practice, because of the disconnect between its high efficacy and low implementation by the practice community. We used the Consolidated Framework for Implementation Research (CFIR) for organizing and guiding development of Implementation Theory $(7,8)$, as a useful framework for an applied approach to Implementation Science (9). A recent change in reimbursement policy regarding the provision of immediate postpartum LARC placement at hospitals providing obstetric care to underserved women represents a major opportunity for improving access to LARC. This strategy illustrates CFIR's usefulness in addressing the challenges of increasing utilization of LARC by the practice community. The five domains of CFIR (Intervention itself, external characteristics, internal characteristics, individual characteristics, and organization change process) are all relevant to LARC adoption. Although research supporting the effectiveness and utility of LARC (the intervention itself) is well documented (1), the other domains involving both institutional and personal factors can constitute major barriers to utilization of LARC for underserved women. These barriers may be particularly formidable in the inpatient postpartum setting where women are attended by OB/GYN physicians. The external institutional level is complicated by 3rd party payer policies that can require modifications to permit LARC initiation during hospitalization for delivery (See Table 1). Reimbursement can also be complicated by internal institutional factors related to billing, pharmacy stocking and access, as well as the clinical staff providing obstetrical care (See Table 1). Public payer systems, such as Medicaid reimbursement, can further complicate institutional challenges (10), which may include policy issues or additional requirements for coding and billing, particularly for safety-net hospitals that rely extensively on Medicaid reimbursement. Table 1 details these challenges to implementation that researchers, physicians and staff encountered as attempts were made to increase access to LARC within the urban safety-net hospital in Florida. Access to LARC within Florida is particularly important as Florida does not have expanded Medicaid and the state agency relatively recently approved LARC for Medicaid reimbursement. 
Table 1

Implementation Context: Issues Experienced in relation to making LARC Accessible

\section{Implementation Other Implementation Activity Construct}

External Organization: Medicaid Approval

External Organization: Safety-net hospital role

External Organization: Managed Care Organizations
The state administrative agency for Medicaid did approve LARC as a Medicaid service and this was a stimulus for the community's implementation efforts. Lack of state agency approval for Medicaid reimbursement was a major impediment to LARC use by economically disadvantaged women.

The local safety-net hospital was established as the local lead site for LARC implementation because of its role in providing service to local Medicaid clients,

Since Florida uses Managed care organizations to administer Medicaid services, the safety-net hospital needed to contract with the Managed Care Organizations. After several years, just when we were completing our focus groups, the hospital obtained a contract form the major Managed Care Organization in our area. Unfortunately, that Managed Care Organization discontinued their service in our area.

Internal

The hospital contract Office required signed contracts to enable hospital billing for Organization: LARC services

Hospital

Contract Office

Internal

Organization:

The billing office can not begin billing until there is a contract.

Hospital Billing

Office

Internal

Organization:

The hospital pharmacy would not stock LARC until contracts and billing were completed.

Hospital Billing

Office

Internal

Organization:

The OB/GYN Department could not administer LARC until pharmacy made LARC available.

OB-GYN

Department

External

Organization:

Other hospitals

Other hospitals in the area have indicated a reluctance to provide LARC since the safety-net hospital (major Medicaid serving hospital) was having so many problems.

Overcoming institutional factors may require extensive organizational change and/or systematic processes to initiate and maintain increased LARC utilization. These processes include quality improvement efforts to overcome the challenges (11) that are reflected in the CFIR domains involving internal organizational characteristics and the adoption process. However, personal factors, particularly patient characteristics, that pose barriers to client utilization due to healthcare organization and system 
insensitivity to patient issues, may also be extensive and challenging. These factors may represent critical considerations in developing effective institutional/organizational practices for increasing LARC utilization.

Patient characteristics related to general use of contraception have been explored in a number of populations, particularly low income minority women, in which the prevalence of LARC use is low. For example, Potter, et al $(12,13)$ conducted open-ended interviews with predominantly Hispanic populations. Other recent qualitative research regarding perceptions of contraception use, specifically LARC use, focused on young/adolescent female populations $(14,15)$. Hodgson, et al $(16)$ used focus groups to better understand the general contraceptive decision making among economically disadvantaged African American women. Hofler, et al (11) used qualitative interviewing with hospital staff to better understand the challenges to LARC utilization. Other research efforts to understand interest in contraception also recommend qualitative interviewing to assess the reasons for using LARC (17).

The need to better understand, through qualitative research, the barriers and issues that impede utilization of LARC with potential patients appears to be well recognized. However, there remains a research gap regarding economically-disadvantaged women living in urban areas, particularly African American women, concerning their use of highly effective contraceptives and their perceived barriers to use or access. Reports regarding the use of these procedures within the context of implementation research theory or applied science are scarce. In-depth interviews and focus group research would be inappropriate for women giving birth while in an urban hospital due to both the stresses of child birthing and newborn infant care, as well as the short term nature of the stay. Accordingly, settings for the qualitative research were selected to engage prospective women of childbearing age in convenient, familiar settings, without the immediate stressors associated with labor and delivery. Within the context of applied implementation science, this study examines beliefs and perceptions of a population served by an academic safety-net hospital, located in a Southeastern U.S. urban neighborhood in which African Americans constitute $80 \%$ of the residents. The county served by this hospital has the largest proportionate population of African Americans (29.5\%) of Florida's 20 counties with the largest populations (range 318,560 to $2,779,322$ ). This county also has the highest rate (41.6\%) of less than 18 month inter-pregnancy intervals among Florida's 20 largest counties in population (low of $4.7 \%$ ).

Our Research Question focused on the need to develop an understanding of the issues and concerns of women that could enhance access to and use of highly effective reversible contraceptives. In particular, we wanted to develop critical insights to facilitate a hospital-based implementation strategy, tailored to women that are served by the primary safety-net hospital that is located in the urban core.

\section{Methods}

We used qualitative methods, specifically focus group interviews, to better understand women's perceptions of LARC (IUDs and implants), barriers to their use and general approaches to family planning. The underlying philosophical assumption of qualitative research that provided a foundation for this study 
was "Pragmatism," which Creswell and Poth (18) summarize as research focused on outcomes of research, and the use of methods, techniques and procedures that best meet the needs and purposes of the study. A "Consolidated Criteria for Reporting Qualitative Research" (COREQ) check list was used as an editing guide to ensure key qualitative research components were included in this report (19).

Since women who receive obstetric care at an urban safety-net hospital were the primary focus of this study, we used a purposeful sampling methodology to reflect the patients served by this safety-net hospital, without being intrusive to the actual child birthing process and newborn infant care. Adult women of childbearing age who were served by the various programs provided in the urban core by the regional Infant Mortality Coalition were recruited because they were likely potential users of immediate postpartum LARC and because of the ethical and logistic challenges of trying to capture women in the hospital in close proximity to childbirth. This study aimed to fill the void in available research in order to facilitate improved outcomes for the specific patient populations that the institution serves. All participants were recruited through a local community based not-for-profit organization (Infant Mortality Coalition, primarily providing services to underserved women of child-bearing age in predominantly African American neighborhoods that are served by the hospital). We held focus groups at three sites in the downtown/urban core of the city served by the hospital, where the community-based organization provides a wide range of women's health programs within urban neighborhoods for underserved women of childbearing age who are primarily African American.

Women were recruited to participate through IRB-approved flyers that were posted and distributed at each of the sites. The flyers solicited participation by women ages 18 to 35 to better understand "women's perspectives regarding family planning goals, current perceptions of contraceptive methods and barriers to family planning." The recruitment process reflected the inclusion criteria of women between the ages of 18 and 35, receiving women's clinical services in the urban core, and the exclusion criteria included females under 18 or over 35 years of age and all males. The flyer also stipulated a 25 dollar gift card as compensation for their time during the focus group. Prior to conducting the interviews, the participants were introduced to the study including their voluntary participation.

Focus group discussions were facilitated by two trained female focus group leaders, who were affiliated with the community-based not-for-profit organization. Both had previous experience leading focus groups and providing family planning services for similar populations. Focus group interview questions were developed through discussions with one faculty and several resident OB/GYN physicians and community-based focus group leaders. Focus group questions followed a specific format, designed to encourage the free flow of thoughts and perceptions in response to broad general questions, while also allowing probes that addressed key questions. Initial focus group questions were very general, related to the women's goals and became increasingly specific to LARC if specific issues involving LARC did not emerge during early discussions.

Each focus group was documented with two to four note takers who were trained to record both verbal and non-verbal communication. Audio recording was not used because of potential intimidation. All 
interviewers and note takers were women to encourage free discussion of issues of concern to women. Focus groups lasted approximately one hour with an additional 30 minutes for food to be served prior to the focus group. Notes were converted into electronic file format (Microsoft Word documents) by each note taker independently prior to any discussion about their content.

Five focus groups were conducted in May and June 2018 in the urban neighborhood where the women were recruited. A sixth focus group was canceled due to the researchers and facilitators agreeing saturation had been reached. These groups included 44 adult female participants, some of whom were accompanied by infants and children. The groups ranged in size from 4 to 17 (median of 8) people. The focus groups were primarily attended by women of childbearing age, although two grandmothers and three male partners accompanied the women, primarily in childcare support roles without participating in focus group discussions. Although self-report demographics of the participants were not collected to provide assurance of anonymity, participants were predominantly African-Americans who had been pregnant at least one time and who received community-based health services in the urban core of the city.

\section{Human Subjects Protection and Consent}

This research was reviewed and approved by a University Human Subjects IRB. The IRB waived a signed written consent based on implied consent and minimum risk.

\section{Analysis}

Notes from the focus groups were then reviewed and discussed by the researchers and note takers using a Content Analysis approach to summarize and synthesize the results. Content analysis is a commonly used qualitative research tool for grouping words, thoughts, ideas and concepts under themes. Additional analysis of the focus group processes was then conducted by the focus group facilitators in collaboration with the lead researchers to discuss and verify the analysis. The use of multiple and varied perspectives in the analysis provided Triangulation, a qualitative analysis approach used to increase credibility and trustworthiness (20). Two senior resident physicians in OB/GYN training, two MPH graduate students, one MPH experienced research/practitioner, and the two community organization facilitators provided medical, public health, and community perspectives.

During our initial review of the focus groups, ten themes emerged from the data. We then prepared the data for sorting, coding, and analysis using ATLAS.ti Software (21). Focus group notes were then coded using the 10 original themes with six additional themes added. The analysis group reconvened to further discuss the coded data and to determine if any themes should be dropped, combined, or split into multiple categories. 
The identified themes and related ideas were also reviewed and interpreted by the focus group facilitators and note takers in relation to how the results could inform contraceptive service delivery. In addition to the themes that emerged from the content analysis of the focus group participant responses, the focus group process, including interactions with the facilitators and voids in the interview responses, provided important insights about the use of contraception. These included the discussion of the women's goals as a prelude to discussing contraception as well as themes that were anticipated, but did not emerge during discussions. These discussions regarding focus group processes led to "lessons learned" in addition to the content analysis.

The focus group results were then analyzed for their relationship to obstetric care. Themes that emerged from the content of the focus group discussions were merged with lessons learned from conducting the focus groups (the focus group process) and were synthesized into 6 overarching and crosscutting themes that focused on improving service delivery for obstetric patients, hospitalized for delivery, a primary purpose of this implementation research.

\section{Results}

Initial issue identification and coding resulted in 16 themes from 5 to 57 different ideas or thoughts associated with these different themes. Many of the thoughts or ideas were associated with multiple themes. Table 2 lists the themes and examples of the ideas or thoughts expressed for each of the themes related to the major overarching theme, "Need for Effective Contraception." Table 3 lists the themes and examples of the ideas or thoughts expressed for each of the themes related to major overarching theme, "Concerns about and Objections to Birth Control", and Table 4 lists the themes and examples of the ideas or thoughts expressed for each of the themes related to the major overarching theme, "Sources of Information and Life Contexts." Notably, the themes are not mutually exclusive with some of the expressed thoughts listed under one theme, but also overlapping with one or more other themes. 
Table 2

Major Overarching Theme: Need for Effective Contraception

$\begin{array}{ll}\text { Theme (\# } & \text { Examples of PARTICIPANT } \\ \text { of times } & \text { COMMENTS } \\ \text { related } & \\ \text { ideas } & \\ \text { appeared) } & \end{array}$

$\begin{array}{ll}\text { Birth } & \text { "Best way to not get pregnant, } \\ \text { Control } & \text { sleep on the sofa" }\end{array}$

(46)

"I have an implant because with work and kids I don't have time for other options. I like knowing it's covered for 2-3 years and I don't need another appointment. Sometimes I get nervous about it working and tap it for good luck and make sure it is still there."

An older woman in the group who is a grandmother shared, "when I gave birth a long time ago, they said we had to wait six months to get birth control. Out of my class, at least half were pregnant again by 6 months. But that was 32 years ago."

"I had a really complicated pregnancy and the birth was traumatic. I don't want to go through that again so I got on birth control right after the birth of my last child."
Education "Didn't do any research before needed(25) choosing a birth control, just went on the pill because it is most common."

"I would want to talk to my OBGYN about birth control."

A participant discussing importance of sexual education for children/teens, "Not everyone has mothers to teach them about these topics."

Trust (23) "I am pregnant with my eighth baby. I had my first at 18 and dropped out of school. Every time
Although the preferred method of birth control varied widely and the discussions regarding risks and benefits of each form of contraception also varied, the majority of the women expressed that family planning is an important part of a women's life and birth control is a significant part of the family planning process.
Many participants state they received most of their information from friends and family; however an unanimously opinion is that a health care provider or OBGYN would be the best person to provide education about contraception.
There was an underlying distrust for the medical field including its health care providers and pharmaceuticals Women were not sure which 


\begin{tabular}{|c|c|c|}
\hline & $\begin{array}{l}\text { I wanted to go back I got pregnant } \\
\text { again. Birth control is not for me, I } \\
\text { am too fertile. I'm going to get my } \\
\text { tubes tied after this one." } \\
\text { "I took the pill for a while. Any } \\
\text { birth control has risks, I am } \\
\text { scared of the pharmaceutical } \\
\text { industry." This participant later } \\
\text { states she does not want more } \\
\text { kids and will "get my tubes cut" }\end{array}$ & $\begin{array}{l}\text { information they have heard about birth control } \\
\text { options via friends/family/TV/social } \\
\text { media/physicians was accurate. Much of this } \\
\text { distrust seemed to stem from fear of side effects } \\
\text { or being harmed by their contraception. }\end{array}$ \\
\hline $\begin{array}{l}\text { Got } \\
\text { pregnant } \\
\text { on birth } \\
\text { control } \\
\text { (11) }\end{array}$ & $\begin{array}{l}\text { "I used to use the pill, and I got } \\
\text { pregnant on it." } \\
\text { "I got pregnant on the pill. But my } \\
\text { cousin had the implant and it } \\
\text { made her arm swell. So now I am } \\
\text { not using anything [for } \\
\text { contraception]" } \\
\text { "I think that is how I got } \\
\text { pregnant." Participant discussing } \\
\text { her birth control pills. }\end{array}$ & $\begin{array}{l}\text { The participants who cited pregnancy while on } \\
\text { contraception also discussed inappropriate use } \\
\text { of their form of contraception at the time of } \\
\text { pregnancy, i.e. forgot to take their oral } \\
\text { contraceptive pills or were late in receiving a } \\
\text { follow-up contraceptive injection. }\end{array}$ \\
\hline $\begin{array}{l}\text { Lack of } \\
\text { control } \\
\text { (12) }\end{array}$ & $\begin{array}{l}\text { "Some people don't want to take } \\
\text { any medication. But natural } \\
\text { doesn't work." } \\
\text { "[a hospital in town] told me that I } \\
\text { can either get me tubes tied after } \\
\text { delivery or wait } 6 \text { weeks to get } \\
\text { birth control." }\end{array}$ & $\begin{array}{l}\text { Women have to rely on the contraceptive options } \\
\text { available within their health care system. }\end{array}$ \\
\hline
\end{tabular}


Table 3

Major Overarching Theme: Concerns about and Objections to Birth Control

\begin{tabular}{|c|c|}
\hline $\begin{array}{l}\text { Theme (\# } \\
\text { of times } \\
\text { related } \\
\text { ideas } \\
\text { appeared) }\end{array}$ & $\begin{array}{l}\text { Examples of PARTICIPANT } \\
\text { COMMENTS }\end{array}$ \\
\hline
\end{tabular}

\begin{tabular}{|c|c|c|}
\hline \multirow{3}{*}{$\begin{array}{l}\text { Got } \\
\text { pregnant } \\
\text { on birth } \\
\text { control } \\
\text { (11) }\end{array}$} & $\begin{array}{l}\text { "I used to use the pill, and I } \\
\text { got pregnant on it." }\end{array}$ & \multirow{3}{*}{$\begin{array}{l}\text { The participants who cited pregnancy while on } \\
\text { contraception also discussed inappropriate use of their } \\
\text { form of contraception at the time of pregnancy, i.e. } \\
\text { forgot to take their oral contraceptive pills or were late in } \\
\text { receiving a follow-up contraceptive injection. }\end{array}$} \\
\hline & $\begin{array}{l}\text { "I got pregnant on the pill. } \\
\text { But my cousin had the } \\
\text { implant and it made her arm } \\
\text { swell. So now I am not } \\
\text { using anything [for } \\
\text { contraception]" }\end{array}$ & \\
\hline & $\begin{array}{l}\text { "I think that is how I got } \\
\text { pregnant." Participant } \\
\text { discussing her birth control } \\
\text { pills. }\end{array}$ & \\
\hline
\end{tabular}




\begin{tabular}{|c|c|c|}
\hline $\begin{array}{l}\text { Lack of control } \\
\text { (12) }\end{array}$ & $\begin{array}{l}\text { "Some people don't want to } \\
\text { take any medication. But } \\
\text { natural doesn't work." } \\
\text { "[a hospital in town] told me } \\
\text { that I can either get me } \\
\text { tubes tied after delivery or } \\
\text { wait } 6 \text { weeks to get birth } \\
\text { control." }\end{array}$ & $\begin{array}{l}\text { Women have to rely on the contraceptive options } \\
\text { available within their health care system. }\end{array}$ \\
\hline $\begin{array}{l}\text { Problems with } \\
\text { pill (14) }\end{array}$ & $\begin{array}{l}\text { "I am on the pill, but it is } \\
\text { hard to remember to take } \\
\text { them. I am thinking about } \\
\text { getting an IUD." } \\
\text { "I think that's how I got } \\
\text { pregnant" said a participant } \\
\text { who was taking birth control } \\
\text { pills when she became } \\
\text { pregnant } \\
\text { "I don't have time to keep up } \\
\text { with the pill. My memory is } \\
\text { bad, and getting an } \\
\text { appointment every } 3 \text { months } \\
\text { for a Depo shot works for } \\
\text { me." } \\
\text { "I am not a good pill taker } \\
\text { with my busy life style so I } \\
\text { have a Nexplanon." }\end{array}$ & $\begin{array}{l}\text { These focus groups reaffirmed the disadvantage } \\
\text { for some women taking contraceptive pills of } \\
\text { having to remember to take them every day. There } \\
\text { were a few women who successfully set alarms } \\
\text { on their phones, however many women cited } \\
\text { inability to remember the pill as a major deterrent } \\
\text { to appropriate use. }\end{array}$ \\
\hline $\begin{array}{l}\text { Side effects } \\
\text { (45) }\end{array}$ & $\begin{array}{l}\text { "An IUD can get lost up } \\
\text { there." } \\
\text { "The shot makes you gain } \\
\text { weight and messes with } \\
\text { your mood." } \\
\text { "My cousin had the implant } \\
\text { and her arm got swollen." }\end{array}$ & $\begin{array}{l}\text { Side effects and misinformation were strongly } \\
\text { related during discussions of contraception, } \\
\text { particularly with LARC. Nonetheless, in many } \\
\text { cases, actual side effects of OCs or injectable } \\
\text { contraception were accurately perceived. }\end{array}$ \\
\hline $\begin{array}{l}\text { Not } \\
\text { ashamed/take } \\
\text { care of kids (4) }\end{array}$ & $\begin{array}{l}\text { "some women feel blessed } \\
\text { to have a child and wouldn't } \\
\text { want to 'block their } \\
\text { blessing"' } \\
\text { "having my son was great } \\
\text { because then I got financial } \\
\text { aid. He was a blessing. [in } \\
\text { regards to finishing her } \\
\text { bachelors degree] }\end{array}$ & $\begin{array}{l}\text { Although unplanned pregnancy may be viewed as } \\
\text { a negative event to many researchers or health } \\
\text { care providers, many women are proud of the } \\
\text { children they have (planned or unplanned) and } \\
\text { take great pride in caring for their children. } \\
\text { Participants in the focus groups verbalized } \\
\text { support for their fellow mothers. }\end{array}$ \\
\hline $\begin{array}{l}\text { IUD } \\
\text { Misinformation } \\
(29)\end{array}$ & $\begin{array}{l}\text { "I have an IUD. I don't like it, } \\
\text { it made my periods irregular. } \\
\text { But I have to wait another } \\
\text { year before I can have it } \\
\text { removed." }\end{array}$ & $\begin{array}{l}\text { Much of the misinformation about IUDs and } \\
\text { implants feeds in to the fears that deter women } \\
\text { from choosing LARC as their form of } \\
\text { contraception. }\end{array}$ \\
\hline
\end{tabular}




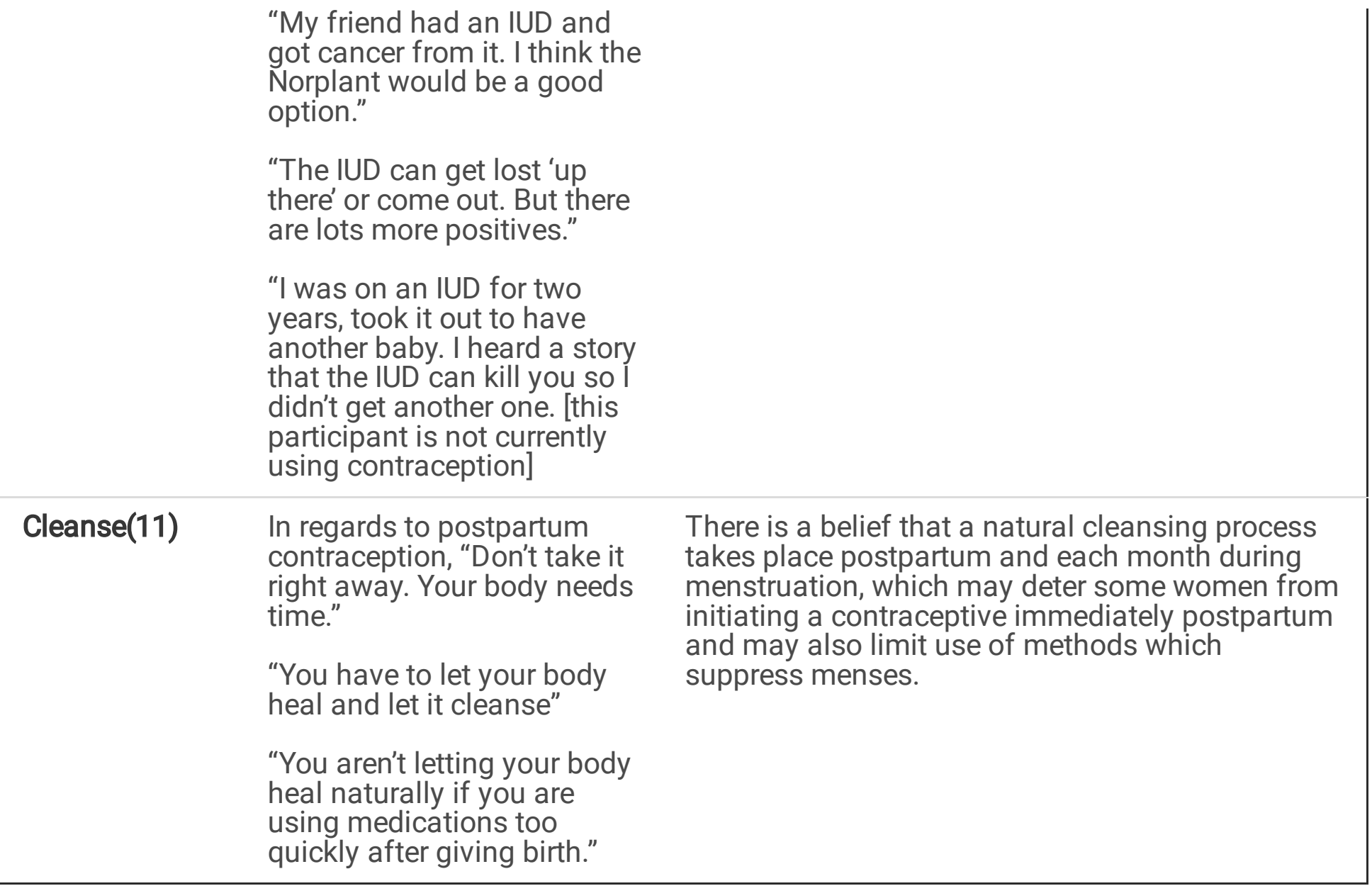




\section{Table 4}

\section{Major Overarching Theme: Sources of Information and Life Context}

\section{Theme (\# Examples of PARTICIPANT INFERENCES \\ of times COMMENTS \\ related \\ ideas \\ appeared)}

\section{Family "I talk to my grandma, my friends, my and auntie, and my pharmacy tech since Friends my mom knows the pharmacist. I don't (13) discredit my mom but I want a professional to ask [questions to about contraception]"}

Social Media(9)
"I have read a lot of bad reviews about birth control online."
"I had an IUD for five years, I was about to go to the doctor to get it replaced, but I saw a post on Facebook about a women who had the same IUD but it traveled and got into her spine and then her toes turned black. I got my IUD taken out and didn't replace it."

\section{Goals}

(13)
"having an unplanned pregnancy would slow down the process" [toward achieving personal goals]
"I was accepted to VCU but being pregnant now, I don't have much family support so I am going to push going back to college back a semester."
"During college you are learning about yourself and get the full college exposure. Having a child would not be a setback but would bring a lot of additional pressure, but begin pregnant does not mean you cannot graduate."

Women's support system represents a key part of their lives, it is important to support their belief system while also providing accurate and up to date information regarding contraceptive options.

Social media has the ability to be used to disseminate accurate health information; however, the accuracy and scientific evidence supporting much of the information disseminated is lacking. Unfortunately much of the information on social media is anecdotal and not based on sound science.
The majority of participants did not perceive an unplanned pregnancy as a barrier to achieving their personal or career goals; however, most agreed that a pregnancy and raising an additional child would delay the achievement of their goals or add additional challenges.

The identified themes and related ideas that were reviewed and interpreted by the focus group facilitators and note takers for their relation to how the results could inform contraceptive service delivery were synthesized into 6 overarching and crosscutting themes.

1. Asking women about their immediate and longer term goals can provide a critical context for framing discussion about the impact of having children and the role of contraception. Therefore, discussions with patients are more likely to be effective when framed within the context of patients' goals.

2. While women's support systems, which could include mothers, grandmothers, other relatives and friends as well as neighbors, may sometimes provide inaccurate information regarding contraception, the 
critical role they provide in the lives of many of these women needs to be appreciated and respected. Therefore, clinicians should acknowledge and respect the support systems that women rely on for child birthing and childcare.

3. Notwithstanding the critical role of support systems, clinicians caring for women represent a trusted and respected source of information. Providing accurate information on contraception options represents a critical role for clinicians.

4. The women interviewed, and presumably many of the women giving birth at this safety-net hospital, have been exposed to and are concerned about information that is inaccurate, misleading, and could interfere with optimal health life choices. In addition to support systems, participants also obtained information from the internet. Some of the most important perceptions that could interfere with optimal health choices that need to be addressed in a positive way are:

a. Contraception is NOT effective. This was a frequently reported concern;

b. Contraception causes intolerable side effects that women fear;

c. Regular 'cleansing' provided by menstruation is vital to women's health;

d. A plan for abstinence is a reliable way to prevent pregnancy.

5. Religious objections to contraception did not emerge during focus group discussion, although these have been reported from other staff and board members of concerned community organizations.

6. Age of women did not appear (based on the subjective observations of the focus group notetakers and facilitators) to impact the need to address the contraceptive-related concerns detailed above. The insights obtained from the focus groups appear to apply to the range of age groups of the participating women whose perspectives were assessed in the focus groups.

\section{Discussion}

Birth spacing and family planning remain a major public health issue, considered one of the ten greatest public health accomplishments of the $20^{\text {th }}$ century $(22,23)$ and providing women the option to choose whether and when to be pregnant enhances maternal and child health (24-26). Focusing on increasing utilization of highly effective reversible contraception (the term, LARC, was not typically used), the findings from this study revealed issues and concerns of a sample population served by the safety-net hospital in a major southeastern city, including: the role of patients' goals in their decision making, the importance of women's support systems, trust and respect for clinicians providing obstetric care, inaccurate and misleading information these women are exposed to, and the absence of religious concerns about contraceptive choices. 
Although a number of published studies have examined barriers to adolescent use of contraception including LARC, we identified a notable void for studies that addressed issues and concerns of adult urban women, particularly African American women $(14,15,27)$. While institutional barriers impede use of LARC, other studies have concluded that addressing misconceptions can reduce disparities in utilization of LARC (28-30). For some populations, immediate postpartum LARC placement also appears to have advantages over other strategies to access LARC (31). This study focused on adult women and identified factors, specific to urban adult women, that can influence decisions to utilize LARC. Although findings about contraceptive use and concerns were similar to other studies, immediate postpartum use of LARC did not emerge as an issue. Our results complement those of other studies with other populations such as adolescents (32). Other studies have also documented high interest in LARC by women who have had recent unintended pregnancies and women who do not want to become pregnant within the next two years (33). In particular, the findings from this study are uniquely positioned to inform implementation strategies designed to overcome impediments to optimal patient decision-making concerning use of contraception.

\section{Implications for Policy and Practice:}

In addition to the potential role of increased LARC utilization to reduce unintended pregnancies and induced abortions $(1,2)$, shorter periods of birth spacing have increasingly been linked to infant $(34,35,36)$ and maternal $(37,38)$ morbidity and mortality. We conducted this study in the county that has the highest $<18$ month interpregnancy interval rate of Florida's 20 largest counties in population size in 2017. The $<18$ month interpregnancy interval rate for this county, with the largest proportionate African American population of Florida's larger counties, was also $19.5 \%$ higher than the state $<18$ month interpregnancy interval rate. Public policies that increase access to LARC by decreasing non evidence-based concerns of women as well as reducing the financial barriers are in the public interest as well as the interest of the women who may receive these services.

While family planning including contraception may primarily reside within the purview of public health, primary care and community-based organizations, healthcare institutions play a key role in facilitating the use of LARC immediately following childbirth. At this critical opportunity for providing LARC, these institutions face challenges not only related to increasing access to LARC, but also to effectively communicate with patients to enable informed patient decision making. Concerns about coercive use of LARC $(39,40)$, appear far less relevant where access to LARC by urban minority women in Florida is so limited.

Although organizational issues tend to be the focus of implementation research, the individual patient issues and concerns regarding contraception in general, and effective reversible contraception, in particular, that were identified through this research can pose a substantial barrier to a patient's decision to utilize LARC during immediately following childbirth. Greater understanding of the issues and concerns of the patient population can enhance provider-patient health communication at this critical 
juncture. Dehlendorf and colleagues (41-43) have extensively documented the need for improvements in patient counseling and education by providers. The results of this study may be especially useful for two major tools for provider-patient communication, Tailoring and Motivational Interviewing, both which

\section{$44,45)$}

47)

We believe these focus group conclusions provide important information which reinforce the basic principles of patient centered implementation strategies such as tailoring and MI based approaches for optimal provider-patient communication related to using LARC. In addition, they can provide clinicians, including those in training, with insights regarding issues important to their patients and facilitate their engaging in effective, empathetic interactions with them.

We found that issues of reproductive coercion associated with contraception did not emerge during these focus group discussions, although these issues have been raised by others in the community. The context that LARC is readily accessible by more economically privileged women and that economically disadvantaged women may have only very limited access to LARC, resulting in denial of effective contraception and greater risk for unintended pregnancy may represent the most relevant social equity issue related to LARC in this population.

The institutional adaptation process represents another key domain of the Consolidated Framework for Implementation Research. Although the provider-patient interaction is only one component of institutional QI, it can be critical to achieving optimal evidence-based outcomes, in this case initiating LARC postpartum, prior to hospital discharge. Key performance metrics for education/counseling can be built into an Electronic Health Record (EHR)-based, simple check list with key points during service delivery (pre- and post-partum). In addition to measurement, data collection and monitoring of key elements of communication, the EHR-based check list can serve as decision support for providers. Key elements such as: a) discussion of patient goals and their relation to having children, b) eliciting and acknowledging support mechanisms, and c) addressing common issues and concerns, could be programmed into the EHR, thereby institutionalizing effective LARC communication as well as providing a mechanism to monitor and track progress related to the primary outcome of patient utilization of LARC.

We suggest that Motivational Interviewing has the potential to counteract inaccuracies and myths in a non-judgmental and respectful manner, particularly since our results indicate the clinicians are relied on to provide accurate information. Consequently, it may be important for providers to be prepared to address some of the common myths such as:

1. Contraception is NOT effective. This common assumption can be addressed by explaining the tiered approach to contraceptive efficacy, detailing how some methods are highly effective (implants, IUDs), while others are moderately effective (pills, patch, ring, injections) and still others are less effective (condom, spermicide, withdrawal). 
2. Contraception causes intolerable side effects that women fear. This concern is best addressed by candidly detailing side effects associated with different contraceptives and addressing fears. In particular, the bleeding changes associated with hormonal contraceptives and IUDs should be candidly reviewed with women considering initiation of this methods. Proactive counselling regarding bleeding changes associated with progestin-only contraceptives has been found to increase user continuation (49).

3. Regular 'cleansing' provided by menstruation is perceived by some women to be vital to women's health. In many cases, explicit discussions with women regarding why regular bleeding is not necessary in women using hormonal contraception can address this myth. In some circumstances, pointing out that breastfeeding and pregnant women do not bleed regularly can be helpful. It may also be helpful to point out that changes in bleeding do not mean the contraceptive's efficacy is diminished. If women concerned about possible negative health effects of not bleeding regularly have access to other women who can describe in a reassuring fashion their own experiences with menstrual changes associated with use of hormonal contraception, this can be helpful. Some women believe that if they do not have regular menstrual cycles, old and unhealthy blood accumulates in their uterus. Acknowledging this concern and pointing out that the lining of the womb becomes thin during use of hormonal contraception or lactation can be helpful.

Our findings from this research have important implications for educational and counseling interventions that have been successfully used to enhance other healthcare services. However, research and evaluation studies will be required to confirm if these approaches are effective in increasing utilization of LARC by urban adult population, particularly immediately following childbirth. This study also has important implications for Implementation Science which tends to focus on organizational factors influencing adoption, while ignoring the need to adapt to concerns of patients. A more patient-centered approach that focuses on patient factors may be critical for more effective adoption of evidenced based interventions, a primary purpose of implementation research.

\section{Strengths And Limitations}

This qualitative research provided valuable insights that can inform Implementation Strategies to enhance utilization of LARC following delivery at a safety net hospital serving urban adult women. A limitation of this study was that it was conducted within a narrow geographic area including limited socio economic and ethnic diversity. However, developing better understanding of this specific population was a primary goal of the study.

\section{Conclusion}

Patient characteristics can be a major factor in increasing the effectiveness of implementing evidencebased science in practice settings, in this case the utilization of LARC. Moving beyond the internal and external organization characteristic associated with effective implementation, this study provided important insights into: 1) potential barriers inherent in the issues and concerns about LARC among 
women who are served by an urban safety-net hospital, and 2) how patient centered implementation strategies such as counseling and education can be developed to overcome those barriers. Utilizing the results of this study to enhance clinician-patient interaction is especially important for overcoming patients' personal concerns and issues that can be barriers to patient use of LARC. Our findings can inform development of Implementation Strategies such as cultural tailoring and MI intervention research or institutional QI projects that are intended to enhance utilization of LARC.

\section{Declarations}

\section{Ethics Approval and Consent to Participate}

This study was reviewed and approved (IRB201801017) by the University of Florida, Human Subjects Research Institutional Review Board (IRB). The University of Florida Human Subjects Research IRB waived a signed written Informed consent based on Implied consent and minimum risk. All methods were performed in accordance with the relevant guidelines and regulations.

\section{Consent for Publication}

Not Applicable.

\section{Competing Interests}

one of the authors (Dr. Kaunitz) consults with Merck and his Department receives research funding from Medicines360. All other authors have no Competing Interests.

\section{Availability of data and materials:}

The raw data and Atlas ti output for this study are archived in protected files for health equity research within the Office of Research Affairs at the University of Florida, College of Medicine-Jacksonville, and are available from the corresponding author on reasonable request.

\section{Funding}

Funds used to support this study were internal to the organizations supporting the study (the University and the community-based organization). No dedicated funds to conduct this research were solicited or obtained.

\section{Authors Contributions}


WCL, KLB; SB, AMK, and LB designed the study and developed the and substantially edited the manuscript. LH and VJ facilitated the focus groups. KLB, SB, LH; VJ, PJG, IM, collected data and with WCL analyzed the data. WCL KLB; SB, AMK, and LB primarily developed discussion, implications and conclusions sections of the manuscript, All authors reviewed, edited and approved the manuscript.

\section{Acknowledgements}

The authors wish to recognize the North East Florida Health Start Coalition, whose support, participation and collaboration was essential for the study.

\section{References}

1. Winner B, Peipert JF, Zhao Q, et al. Effectiveness of long-acting reversible contraception. N Engl J Med 2012, 366(21):1998-2007.

2. Secura GM, Madden T, McNicholas C, et al. Provision of no-cost, long-acting contraception and teenage pregnancy. N Engl J Med 2014, 371(14):1316-23.

3. Dehlendorf C, Park SY, Emeremni CA, et al. Racial/ethnic disparities in contraceptive use: variation by age and women's reproductive experiences. Am J Obstet Gynecol. 2014, 210(6):526.e1-9.

4. Thiel de Bocanegra $H$, Braughton $M$, Bradsberry $M$, et al. Racial and ethnic disparities in postpartum care and contraception in California's Medicaid program. Am J Obstet Gynecol. 2017, Jul;217(1):47.e1-47.e7.

5. Kavanaugh ML, Jerman J. Contraceptive method use in the United States: trends and characteristics between 2008, 2012 and 2014.Contraception. 2018 Jan;97(1):14-21.

6. Finer LB and Zolna MR. Declines in Unintended Pregnancy in the United States, 2008-2011. N Engl J Med. 2016, 374(9):843-52.

7. Damschroder LJ, Aron DC, Keith RE, et al. .Fostering implementation of health services research findings into practice: a consolidate framework for advancing implementation science. Implement Sci. 2009, 4:50.

8. Damschroder LJ and Lowery JC. Evaluation of a large-scale weight management program using the consolidated framework for implementation research (CFIR). Implement Sci. 2013, 8:51.

9. Livingood WC, Bilello L, Lukens-Bull K, et al. Implementation Research as Applied Science: Bridging the Research to Practice Gap. Health Promot Pract. 2020 Jan;21(1):49-57.

10. Bennett CJ and Mannel R. Walking the Medicaid Policy Tightrope Between Long-Acting Reversible Contraception and Lactation. J Hum Lact. 2018, (3):433-437.

11. Hofler LG, Cordes S, Cwiak CA, et al. Implementing Immediate Postpartum Long-Acting Reversible Contraception Programs. Obstet Gynecol. 2017, (1):3-9.

12. Potter JE, Hubert C, Stevenson AJ, et al. Barriers to Postpartum Contraception in Texas and Pregnancy Within 2 Years of Delivery. Obstet Gynecol. 2016, (2):289-96. 
13. Potter JE, Coleman-Minahan K, White K, et al. Contraception After Delivery Among Publicly Insured Women in Texas: Use Compared With Preference. Obstet Gynecol. 2017, (2):393-402.

14. Hoopes AJ, Gilmore K, Cady J, et al. A Qualitative Study of Factors That Influence Contraceptive Choice among Adolescent School-Based Health Center Patients.

J Pediatr Adolesc Gynecol. 2016, (3):259-64

15. Coates C, Gordon CM, Simpson T. A Qualitative Study Exploring Contraceptive Practices and Barriers to Long-Acting Reversible Contraceptive Use in a Sample of Adolescents Living in the Southern United States. J Pediatr Adolesc Gynecol. 2018 (6):605-609

16. Hodgson EJ, Collier C, Hayes L, Curry LA, Fraenkel L. Family planning and contraceptive decisionmaking by economically disadvantaged, African-American women. Contraception. 2013, (2):289-96.

17. Tang JH, Dominik RC, Zerden ML, Verbiest SB, Brody SC, Stuart GS. Effect of an educational script on postpartum contraceptive use: a randomized controlled trial. Contraception. 2014, (2):162-7.

18. Creswell JW, Poth CN. Qualitative Inquiry and Research Design Choosing among Five Approaches. 4th Edition, SAGE Publications, Inc., Thousand Oaks. 2018.

19. Tong A, Sainsbury P, Craig J. Consolidated criteria for reporting qualitative research (COREQ): a $32-$ item checklist for interviews and focus groups. Int J Qual Health Care. 2007, (6):349-57.

20. Raskind IG, Shelton RC, Comeau DL, Cooper HLF, Griffith DM, Kegler MC. A Review of Qualitative Data Analysis Practices in Health Education and Health Behavior Research. Health Educ Behav. 2019 Feb;46(1):32-39.

21. ATLAS.ti Version 7.5 ATLAS.ti. Scientific Software Development GMBH. Qualitative Data Analysis. 2014.

22. Centers for Disease Control and Prevention. Achievements in public health, 1900-1999: Family planning. MMWR Weekly. 1999, (47):1073-80.

https://www.cdc.gov/mmwr/preview/mmwrhtml/mm4847a1.htm

23. US Department of Health and Human Services. Healthy People 2020: Family Planning Goal. 2010. Available from: https://www.healthypeople.gov/2020/topics-objectives/topic/family-planning https://www.healthypeople.gov/2020/topics-objectives/topic/family-planning

\section{Ahrens KA, Hutcheon JA. Birth Spacing in the United States-Towards Evidence-Based Recommendations. Paediatr Perinat Epidemiol. 2019, (1):01-04}

25. Hutcheon JA, Nelson HD, Stidd R, Moskosky S, Ahrens KA. Short interpregnancy intervals and adverse maternal outcomes in high-resource settings: An updated systematic review. Paediatr 
Perinat Epidemiol. 2019, (1):048-059.

26. Ahrens KA, Nelson H, Stidd RL, Moskosky S, Hutcheon JA. Short interpregnancy intervals and adverse perinatal outcomes in high-resource settings: An updated systematic review. Paediatr Perinat Epidemiol. 2019, (1):025-047.

27. Gilliam ML, Davis SD, Neustadt AB, Levey EJ. Contraceptive attitudes among inner-city African American female adolescents: Barriers to effective hormonal contraceptive use. J Pediatr Adolesc Gynecol. 2009, (2):97-104.

28. Zerden ML, Tang JH, Stuart GS, Norton DR, Verbiest SB, Brody S. Barriers to Receiving Long-acting Reversible Contraception in the Postpartum Period. Womens Health Issues. 2015, (6):616-21.

29. Pritt NM, Norris AH, Berlan ED. Barriers and Facilitators to Adolescents' Use of Long-Acting Reversible Contraceptives. J Pediatr Adolesc Gynecol. 2017, (1):18-22.

30. Goodman M, Onwumere O, Milam L et al. Reducing health disparities by removing cost, access, and knowledge barriers. Am J Obstet Gynecol. 2017, (4):382.e1-382.e5.

31. Bernard C, Wan L, Peipert JF, Madden T. Comparison of an additional early visit to routine postpartum care on initiation of long-acting reversible contraception: A randomized trial. Contraception. 2018, (3):223-227.

32. Sangraula M, Garbers S, Garth J, et al. Integrating Long-Acting Reversible Contraception Services into New York City School-Based Health Centers: Quality Improvement to Ensure Provision of YouthFriendly Services. J Pediatr Adolesc Gynecol. 2017, (3):376-382.

33. Tang JH, Dominik R, Re S, Brody S, Stuart GS. Characteristics associated with interest in long-acting reversible contraception in a postpartum population. Contraception. 2013, (1):52-7.

34. Schummers L, Hutcheon JA, Hernandez-Diaz S, et al. Association of Short Interpregnancy Interval With Pregnancy Outcomes According to Maternal Age. JAMA Intern Med. 2018, 178(12):1661-1670.

35. Yaya S, Uthman OA, Ekholuenetale M, et al. Effects of birth spacing on adverse childhood health outcomes: evidence from 34 countries in sub-Saharan Africa. J Matern Fetal Neonatal Med. 2019, 10:1-8.

36. Conde-Agudelo A, Rosas-Bermúdez A and Kafury-Goeta AC, Birth spacing and risk of adverse perinatal outcomes: a meta-analysis, Journal of the American Medical Association, 2006, 295(15):1809-1823.

37. Ganatra B, Faundes A. Role of birth spacing, family planning services, safe abortion services and post-abortion care in reducing maternal mortality. Best Pract Res Clin Obstet Gynaecol. 2016, (36):145-155.

38. Conde-Agudelo A, Rosas-Bermúdez A and Kafury-Goeta AC, Effects of birth spacing on maternal health: a systematic review, American Journal of Obstetrics \& Gynecology, 2007, 196(4):297-308.

39. Gomez AM, Fuentes L, Allina A. Women or LARC First? Reproductive Autonomy and the Promotion of Long-Acting Reversible Contraceptive Methods. Perspect Sex Reprod Health. 2014, 46(3): 171-175. 
40. McClain D. Birth-Control Experts Are Wary of Coercive Tactics in the Push for IUD Use. The Nation. 2015. Available from: https://www.thenation.com/article/archive/birth-control-experts-wary-ofcoercive-tactics-in-push-for-iud-use/

41. Dehlendorf C, Anderson N, Vittinghoff E, et al. Quality and Content of Patient-Provider Communication About Contraception: Differences by Race/Ethnicity and Socioeconomic Status. Womens Health Issues. 2017, (5):530-538.

42. Dehlendorf C, Kimport K, Levy K, Steinauer J. A qualitative analysis of approaches to contraceptive counseling. Perspect Sex Reprod Health. 2014, 46(4):233-40.

43. Dehlendorf C, Levy K, Kelley A, et al. Women's preferences for contraceptive counseling and decision making. Contraception. 2013, 88(2):250-6.

44. Hawkins RP, Kreuter M, Resnicow K, et al. Understanding tailoring in communicating about health. Health Educ Res. 2008, (3):454-66..

45. Whitney E, Kindred E, Pratt A, et al. Targeting and tailoring message-framing: the moderating effect of racial identity on receptivity to colorectal cancer screening among African-Americans. 2018 Jun 7.

46. Henry Akintobi T, Trotter J, Zellner T, Lenoir S, Evans D, Rollins L, Miller A. Outcomes of a Behavioral Intervention to Increase Condom Use and Reduce HIV Risk Among Urban African American Young Adults. Health Promot Pract. 2016, (5):751-9. ]

47. Lundahl B, Moleni T, Burke Bl, et al. Motivational interviewing in medical care settings: a systematic review and meta-analysis of randomized controlled trials. Patient Educ Couns. 2013, (2):157-68.

48. Tomlin K, Bambulas T, Sutton M, et al. Motivational Interviewing to Promote Long-Acting Reversible Contraception in Postpartum Teenagers. J Pediatr Adolesc Gynecol. 2017, (3):383-388.

49. Whitaker AK, Quinn MT, Munroe E, et al. A motivational interviewing-based counseling intervention to increase postabortion uptake of contraception: A pilot randomized controlled trial. Patient Educ Couns. 2016, (10):1663-9. 